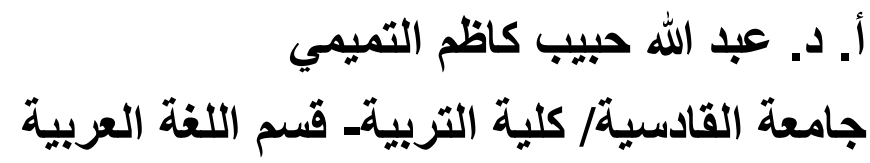
abdallh.kadhm@qu.edu.iq

الباحثة جنان كعيم غازي الخزاعي جامعة القادسية/ كلية التربيةـ قسم اللغة العربية alkhazaalijinan@gmail.com

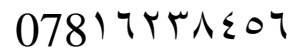

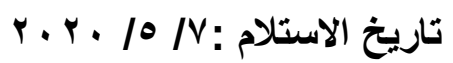

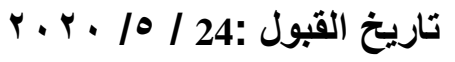

الخلاصة : - (الخ

أن عرض مسألة التداخل بين الثعر والحكاية والثعر والقصة قد أدرك النقاد أنه لايمكن الفصل بين الثعر والحكاية أو الثعر والقصة لأن الغرض نابع من تلك الظاهرة الفنية المتداخلة في البنية الثعرية فهما في تكوين ، وطابع الثعر العربي وبنيته القديمة والحديثة ، فأخذت الحكاية الثعرية والقصة الثعرية ابعادهما المختلفة في السرد الثعري الذي يأخذ فيه الثاعر أسلوبه معتمداً على الاحداث ضمن أطار البناء المحدد بالزمان والمكان والذي يعبر فيه عن فكرته فتلعب فيهما الثخصيات دوراً هاما ومحركاً للأحداث وقد اعتمد ببناء الثكل الحكائي للحكاية والقصصي للقصة على رؤيته التي تأخذ دورها في مضمونها الفني الجديد.

فالحكاية عالم خيال الثاعر وادراكه في آن واحد يخرج بها بمحلته الفكرية من واجهة تجربته الموضوعية فيصيغها من ذلك الواقع المحسوس إلى عالم يفوق ويخرج عن نظام الواقع ،التي تختلط فيه العوالم الجديدة وتتعدد إلى عوالم أخرى فقد أخذ من 


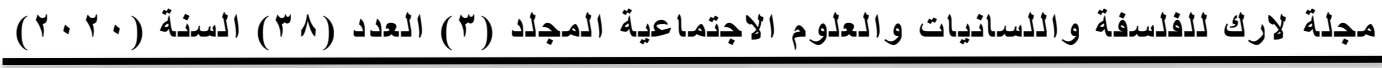

حكاية شهرزاد رمزاً لتثكيل حكاية العراق ، والتي تعد من الموروث الثعبي الخصب التي طلّ عليها الثاعر من نافذة ثقافته لها لها من تأثير على المتلقي ، أما القصة الثعرية فقد عالج بها مشاكل الحاضر بصراعات الماتي لهاضي التي تحاكي القضايا الآنية فلجأ إلى الأسلوب القصصي الذي يتمحور بالوصف وإلى سرد قصص الواقع التي ترد في القرآن الكريم كقصة يوسف (الئليّز)

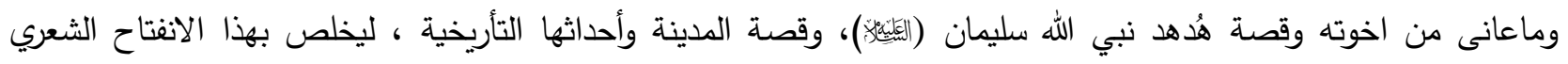
بميزات سردية قائمة على أمتصاص أنماط القصة وايجاد النزعة الجديدة في محاولة تلوين فاعلية بنية الثعر ومسايرة الأحداث الواقعية .

الكلمات المفتاحية : الثعر ، الحكاية ، القصة ، ولاّء الصوّاف . 
The Tale and the Story in the poetry of Wala'a Al-Sawaf

Prof. Abdullah Habib Kazim Al-Tamimi

abdallh.kadhm@qu.edu.iq

Researcher Jinan Kaiem Ghazi Al-Khuzai

alkhazaalijinan@gmail.com

College of Education / University of Al-Qadisiyah

\begin{abstract}
That presented the issue of interference between poetry and the tale or between poetry and the story Critics have realized It is inseparable them( between poetry and the tale or between poetry and the story) Because the purpose stems from this artistic phenomenon intertwined in the Poetic structure. They are in the composition and character of Arabic poetry Its structure is old and modern, The poetic tale and story took on different dimensions. In poetic narration in which the poet takes his style based on events within the framework of the construction specified in time and space in which he expresses his idea, in which the characters play an important role and an engine for events he intentionally built the tale form of the tale and the story form of the story on his vision, which takes its role in its new artistic content, The story is the realm of the poet's imagination and his awareness that one brings out his intellectual acumen from the front of his objective experience, shaping it from that perceptible reality to a world that transcends and exits from the reality system, In which new worlds mix and multiply to other worlds, He took from the tale of Sherazade a symbol to form the tale of Iraq, Which is one of the fertile heritage inherited by the poet from the window of his culture because of its influence on the recipient, As for the poetic story, he dealt with the problems of the present with the conflicts of the past that simulate the immediate issues, So he resorted to the narrative style described which is centered around the description and to tell the stories of reality that are mentioned in the Holy Quran, such as the story of Joseph, Peace be upon him, and what he suffered from his brothers and the story of the prophet Suleiman, and the story of medina and its historical events, To conclude with this poetic openness with narrative features based on absorbing story styles and finding new tendency in an attempt to color the effectiveness of the hair structure and keep pace with real events.
\end{abstract}

Key words : poetry, Tale, Story, Wala'a Al-Sawaf 


$$
\text { الثعر والحكاية }
$$

يلجأ الثاعر إلى البناء الحكائي بوصفه اتجاهاً شِعرياً حداثوياً ماثلاً فيه إلى انفتاح أسلوبه الثِعري عبر تغذية عناصر آلياته

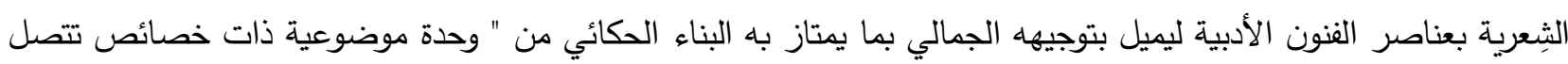
بحال المضمون الذي تحكيه القصيدة أو الواقعة التي تتفعل بحكايتها، ثم إن القصيدة الحكائية بالمعنى الفني تضفي على بنى بنائها العام وحدة عضوية بسبب وحدة الموضوع والمشاعر والصور والأفكار بالثكل الذي تتكامل في بنية القصيدة ذاتياً " (الصكر ،999 ام: صو صو Y)، وتُسبك جوهر صداها من إتقان تجربة الثاعر الذاتية " التي ترتبط أثد الارتباط بأفكار الإنسان

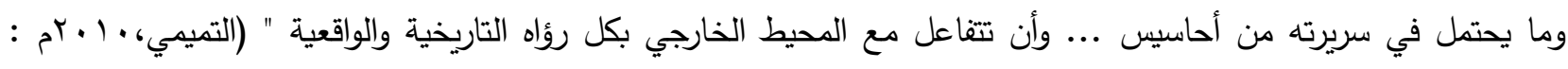

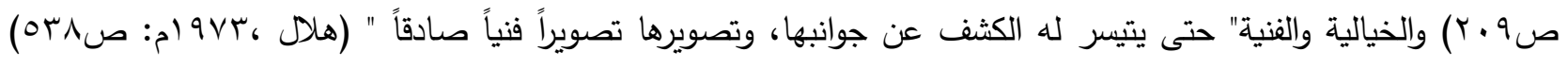
ليطبقها على واقع الحياة في كثف الأحداث بطرح القضايا وتسليط الضوء على الحالة النفسية والثعورية للشخصية المحكي عنها، " والاتساق شرط لا تقوم به وحدة النص إلا إذا عضده شرط آخر هو الانسجام، لا يتّم به النص إلا إذا ألفينا مقصداً

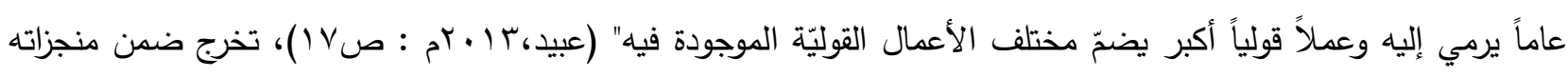

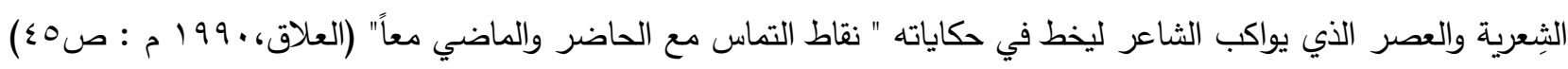
فيغور الثاعر في سرديته الحكائية بتياره المشحون بالإضاءة والخوف، ليحكي ضمن حاجته العميقة كي يخرج من قيوده الذاتية، فيقوى بفاعلية التتفيس الذاتي التي تتبعث من رؤياه للحياة والعالم في مقتضاها الحسي والحركي، فتمنح المتلقي تتابع الحدث لتئل ووحدة التجربة الإنسانية.

قد وظلَّف الصوّاف الحكايات في نصوصه بكسره للحواجز التقليدية بين ماهو سردي وشِعري وتواصله بين الأجناس الأدبية كي ييني تبادلاً للمزايا الداخلية وتوسيع مداها مع احتفاظ القصيدة الثِعرية بخصوصيتها وكيانها على الرغم من تلمس آليات السرد لها، والحكايات عند الصوَّاف تخرج من تجربته التي يحمل بها أسلوبه البنَّاء وتعبيره في شِعريته.

ويعدد الثاعر في نص" كفن شهريار" حيث يسرد حكاياته إلى تجنبه السقوط في الذاتية المغلقة، ويتقدص فرصته في طرح المشكلات بقيمتها الفكرية في تدوين شهرزاد حكاية العراق على كفن شهريار الذي لم يسمعها منها في حكايات ألف ليلة وليلة،

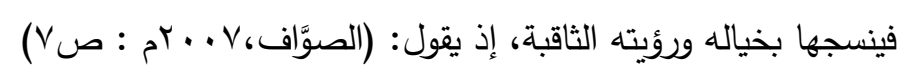

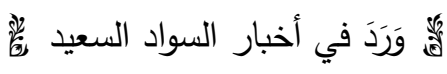

إنّ عبداً إبتتى حُلُماً

$$
\text { في الأعالي }
$$

فوقَ ذؤباتِ النخيل

لوّح للحُلم كثيراً

مِنْ ألفِ عامِ وعامْ 
أنقّلهُ القيذُ

فاستحال القيدُ يمامُ

يفتتح النص بحكاية من حكايات العراق السعيد، وخبر من أخباره، على اساسٍ أنَّ الحكاية العراقية " من أعرق الحكايات في العالم ولعلها هي المنبع الأول لأغلب الحكايات .. التي مرت على هذه البقعة والثعوب التي تداولتها منذ أيام السومريين

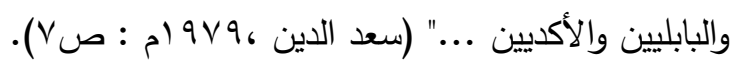

لقد بُني ذلك على وفق تدرُج حكائي موضوعي في تصوير الوضع الاجتماعي لبناء الحلم وأمل تحقيقه ، يرسمه على الأماكن

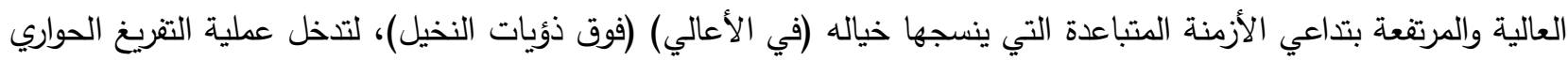

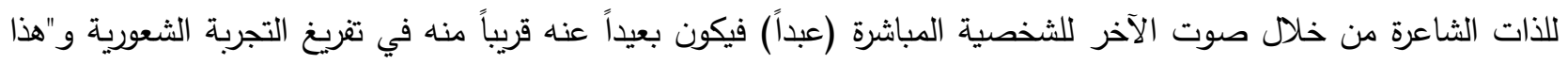

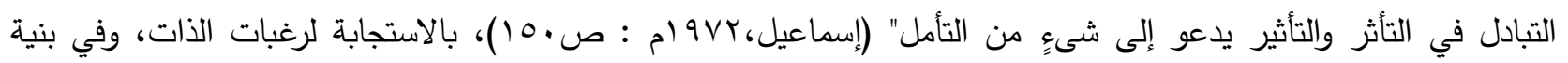

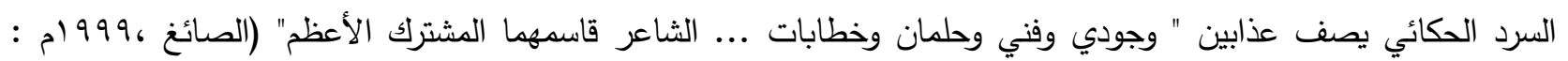
ص با7)، ولا تمثل له خيبة أو خسارة وإنما التفكير بكسر القيود وتحطيم المستحيل على مدار السنين في تجسيد قابلية الحركة ما وفاع بين الماضي والحاضر الذي" يمثل قابلية الثِعر على الائتلاف مع تقلبات يُمكن أن تتحرر من أصولها الأجناسية لتتخلق من

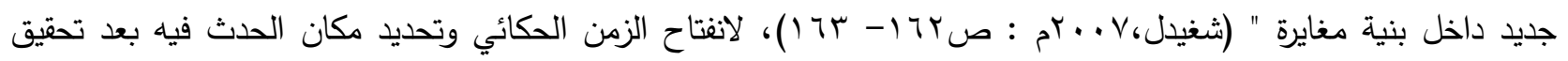

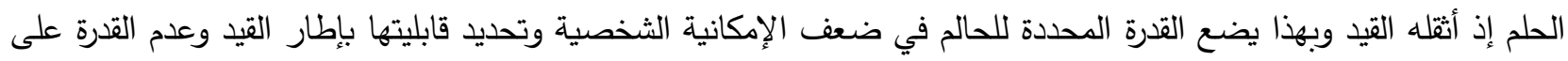
كسره، ويسند تقابلاً جدلياً ما بين القيد الذي يكبل الأحلام والحرية، واليمام الذي يتصف بالئ إلحرية والتحليق كرابط مجازي عقلي باستحالة أن يكون القيد يمام وهذا يسجل موقف الثاعر ورؤيته للواقع والمستقبل المقيد لوحدة الثعور الإنساني التي يعاني منها لئها لئها كل فئات المجتمع.

يتواصل الشاعر بالحكاية التي تتمركز وتأخذ موقع المتن من حكايات شهرزاد للشخصيات المهمة في المجتمع والتي يدخلها

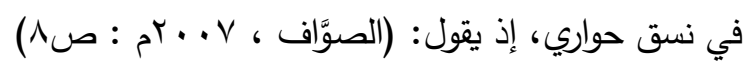
الهوامش:-

وربما! من أكمامها تخرج الحكايا كما السحرة رُبَّما إلا واحدةً خرجت من ذاكرة القتلى 
يوم أمطرت السيف أعتاقاً

وتهاوتْ

دون الرؤوس أحلامُها

شهريار

من بين ألف قتيلٍ وقتيل

أيهمو أنت ...

تتمو الحكاية بوصفها فعلاً شِعرياً داخلياً يطرح قضية الهوامش ضمن حكايات شهرزاد لتجوَّل إلى نوعٍ من القضايا الفكرية والموضوعية التي تحمل طابع " الحس المأساوي حس يتجاوز الحزن ويعلو عليه، أي يتجاوز الكيان الشخصي إلى الكيان الكلي

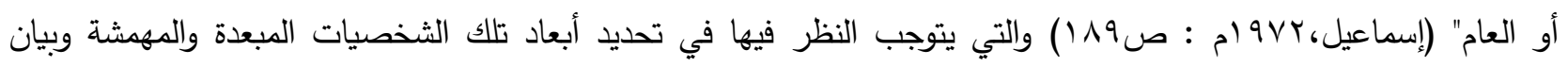

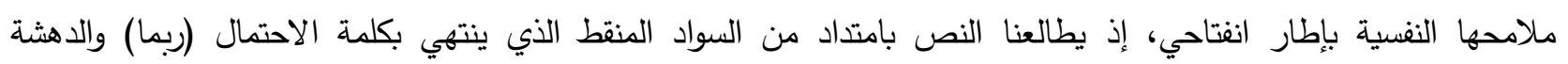
والتعجب (!)، امتداداً لاسترخاء الذات وتأملها الشعوري في مكنون الحكاية ودهشته لطبيعة خروجها، في احتمال خروج حكاية

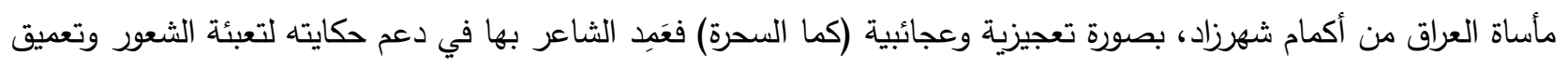
الوعي في تحريك المحور المركزي الذي تدور حوله الأحداث بالاعتماد،على فكرة العنصر المهيمن في الكثف عن الملامح

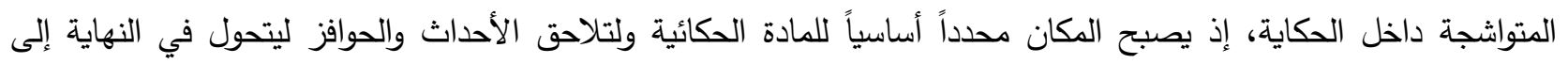

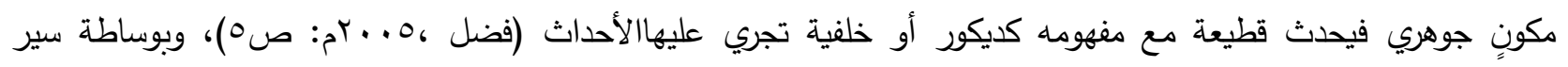
الأحداث يعمل على تماسك الفكرة وبناء صورتها المتتابعة والمتسلسلة في أجزائها لتكون أكثر تلاحماً، فيكرر الاحتمال ارُبَّماه بخروج الحكاية المؤلمة والمفجعة واستثناء واحدة خرجت من ذاكرة القتلى فينجز بهذا التعبير المجازي الذي يكمن في مدلوله الحكائي بقضية سالفة في" انتمائها لنا عبر حكي تاريخنا فيها وتاريخها فينا- في الحكاية - روايتها وتذكّرها واستحضارها -

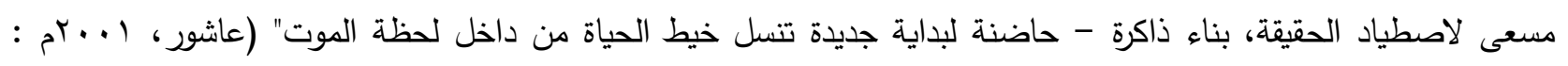

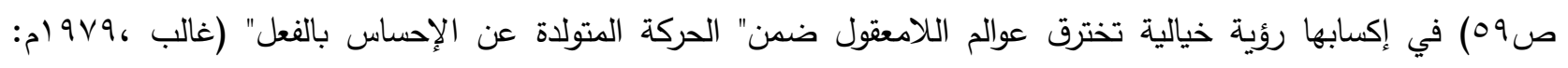
ص • r )، بتهاوى الأحلام والطموحات والأهداف بدل الرؤوس، والتنازل عن حقوق الثخصية الذاتية، وهذه البنية الدائرية داخل

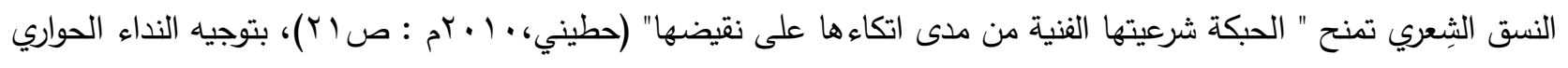
إلى " شهريار" في استدعاء شخصيته والبحث عن الأسرار الكامنة فيها، كرمز للبغض والهمجية وقد حاولت شهرزاد تغييره بالحكمة والدهاء في " تحويل العلاقة المبنية على العنف والقهر إلى علاقة مبنية على الرقة والوداعة بفضل العقل والإقناع"

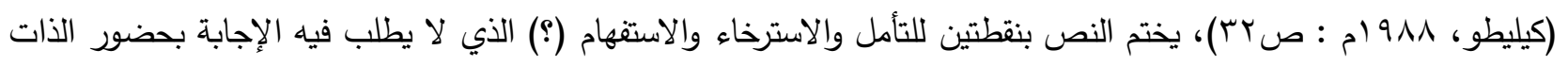

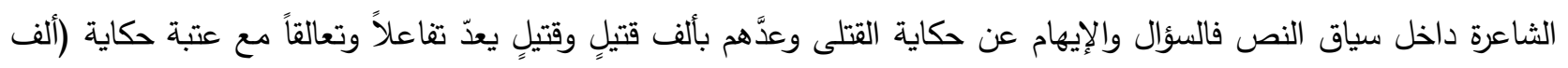

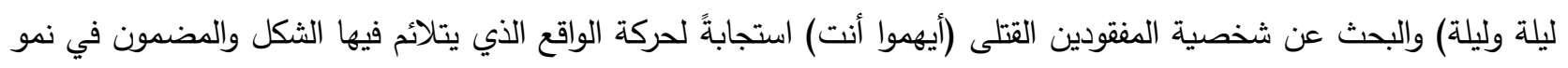
عناصر الحكاية "باستقطاب الوحدات الثانوية في حركة من الزمان والمكان ومن الحالة إلى الموقف ومن الحلم الرومانسي إلى في

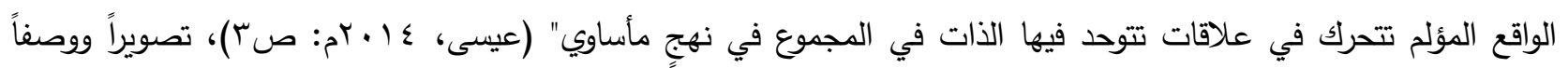
لمعظم قطاعات الحياة الإنسانية والأحداث التي شهدتها البلاد العربية على مدار فئِ السنين. 


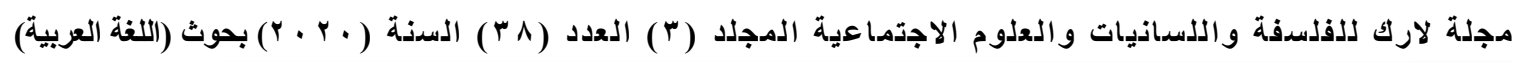
وفي آخر النص يختم الحكاية باستدراكها فيقول (الصوّف، V... Yم : ص10): * استدراك * في ساعة الصفرِ وعندَ خِط الشُروع قطفَ زهرةَ ليلك لم يعلْ إنه قطفَ جسدِه وأودَعَ سرّهُ الأرضَ الحرام ..

يفرد الثاعر استتاجاته الحكائية " على صعيد تثغيل هذه العتبة تثغيلاً أعمق وأوسع وأكثر تأثيراً في بنية القصيدة"

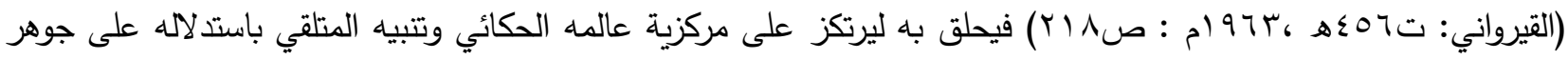

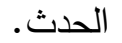

وفي المقطع الاستهلالي يستدرك الثاعر الحكاية ضمن محور الزمان وفاعلية المكان ليثير الحدث لشخصية المحكي عنه" ليرسم لنا في كل نستِ صورةً حسيةً للتعبير عن أحاسيسه الحزينة المتقدة... بما يحمله من مفارقة بأنساقه التصويرية المُعبّرة عن شعورٍ صادقٍ" (كتيب،ه 1 •rم : ص1ه)، في رثاء الثخصية، ضمن استدراكاته الذهنية والخيالية، بتوقف الزمن (في ساعة

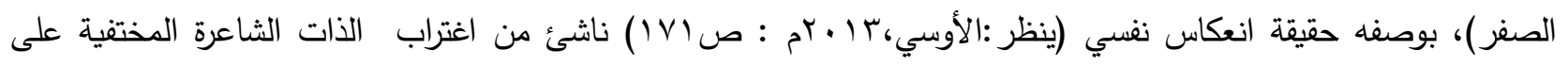
هيئة بصمة متواشجة داخل البنية الحكائية وسرديتها كوحدة عضوية " تامة الخلق والتكوين ... تجمع فيها إحساسات الثاعر

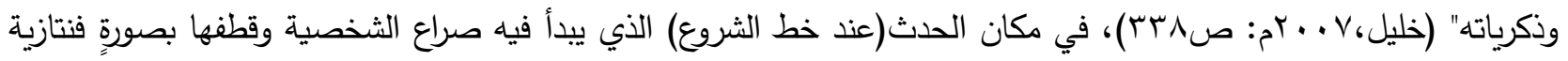
محركةٍ الإحساس المتلقي في تثكلها الجمالي الذي يخترق صورة المحسوس لافتاً النظر إلى عمق بؤرة الحدث وأهمية الشخصية في عرض قضيتها بقطف الجسد وإيداع سره الأرض الحرام ليكثف "عن إثكالية في المنظور المكاني ... وحراكاً مستقبلياً متجهاً

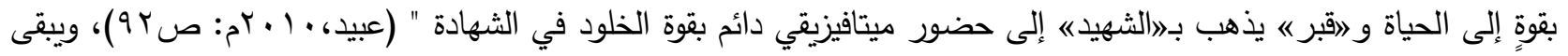
الإحساس بالفقد للشخصية الغائبة داخل الإطار الاجتماعي مندمجاً بين حزن الفقدان والغياب الملتبس داخل الحدث الثراء الراهن، فالثاعر "أراد التعبير عن رؤية أكثر من مجرد الحكاية لحادثة بعينها، رؤية شديدة التكثيف لكثف واقع المواطن العربي"

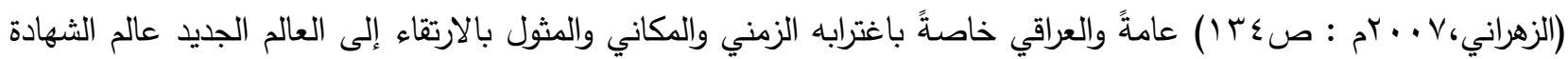
والخلود في أرض المعركة.

$$
\begin{aligned}
& \text { يختم الحكايات التي أوردها في (كفن شهريار) ، بقوله (الصوّاف، V ·. .rم : صrه ): } \\
& \text { حين تصمُتُ يا أُثيب ....... }
\end{aligned}
$$


في الكفن متسعُ للحكاية التي لم ..........

يخاطب الثاعر شخصية الرمز (أُثيب) بتوجيه الخطاب إلى الذات الثاعرة التي تتوارى خلف الرمز بالإشارة إلى المتلقي في النظر إلى شخصية السارد الذاتي ويمد النسق الثِعري بالفراغ المنقط بالسواد لترك مساحة من التأويل والإجابة للمتلقي كي يمكنه

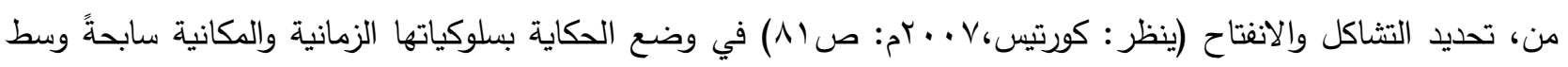

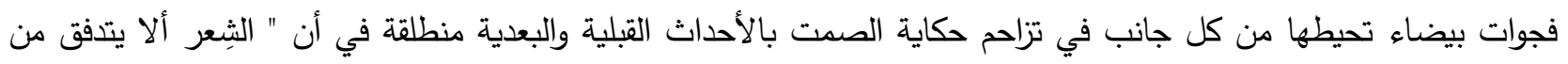

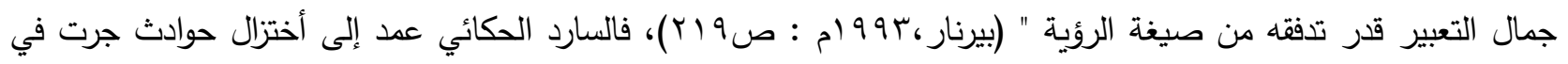
مدة زمنية طويلة بأسطرٍ معدوداتٍ،لأن الثعر جنس أدبي قائم بذاته يعتمد على الأختصار في سرد أحداث الحكاثل الحكاية . ومن أنماط الحكايات التي تأخذ تثكلاً فنيًا ورمزيًا في بنية الحوار الحكائي الغرائبي للذات الثاعرة مع الوجود في نص (هل تكتم

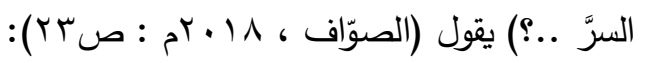

$$
\begin{aligned}
& \text { ما قاله الطيرُ للغيم ... ما قاله الغيم لي } \\
& \text { ما لم أقله لبني بضفيرة يجوب السَّواد }
\end{aligned}
$$

تحمل الحكاية أحداثها المتعاقبة من خلال بداية النص في بنية العتبة وتثكلها بالصورة الاستفهامية لكتمان السر فيدخل في " مقاربات خاطفة لا تكاد تخرج كثيراً عن الحساسية الماثلة المهيمنة التي أثناعها التلاحم بين عتبة العنوان وبنية الاستهلال

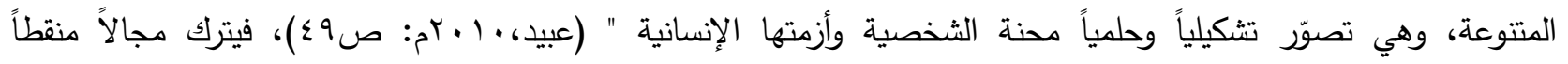

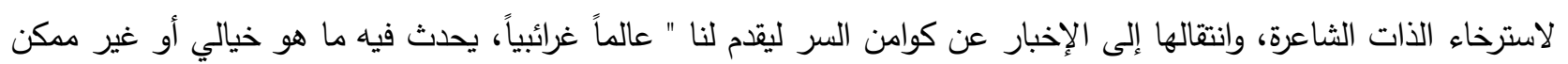
منطقياً، لكنه منجز سردي بقوة منطق الحكاية ذاتها " (الصكر،999 (1م : ص.0.01) في إخبار الطير للغيم وإخبار الغيم للذات الثاعرة ليدخل بالأنفتاح الحواري على الحدث الوجودي في الكثف عن خلجان الأبعاد الفكرية والنفسية والاجتماعية للشخصيات ولأفكار ذات الحاكي، في تبادل أطراف الحديث الإخباري وتعدد الأصوات الحكائية التي تتدرج عبر الاسترجاع الزمني والقضاء المكاني الممتد والمرتفع في الأُقق الكوني ضمن تماسك سردي فالاخبار للشخصية الرمزية الصوفية، تدخل في تمحور حكائية الذات ضمن انتقالات مختلفة ومتعددة في توليد صراع نفسي وذاتي على مستوى سردية الحكاية بإنجاز الاستعارة الذهنية وتوليد خلق الصورة الحكائية في تحريك بؤرة الحدث وتدوير المكان في "الطريقة الفنية الممكنة التي تمتزج بها الأزمنة والأمكنة"

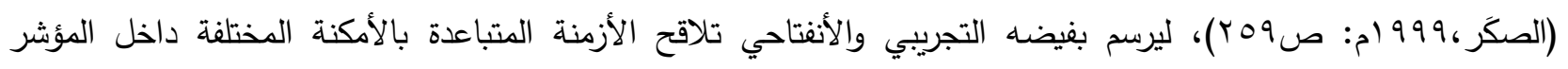
الحكائي، فيبرق سيميائية متجانسة ضمن رؤيته الخيالية التي يحمي بها إبداعه الذاتي والتكنيكي.

فالحكاية عند الصوّاف خطاب استرجاعي يحكي بها السارد أحداثها ضمن نقطة زمنية خزنتها الذاكرة فيقترب بها من رؤيته الخيالية العجائبية المتمحوة في المكان والزمان وقد تعامل الثاعر مع هذا المنطلق المنفتح من مركزية انطلاق خيوط وجذور حكايات التأريخ التي تمسرح بها الحاكي على مستوى الحدث والثخصيات . 
القصة بوصفها جنساً أدبياً فيه وصف للحياة والأثخاص والأحداث، وتوطد اهتمامها بالصراع النفسي للثخصية ذلك أن "

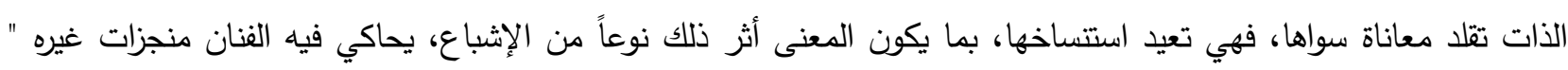

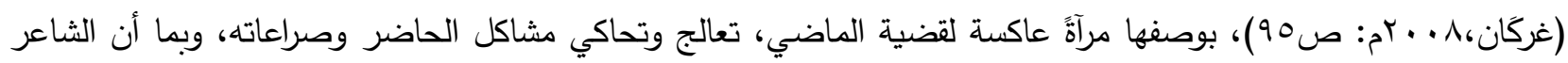

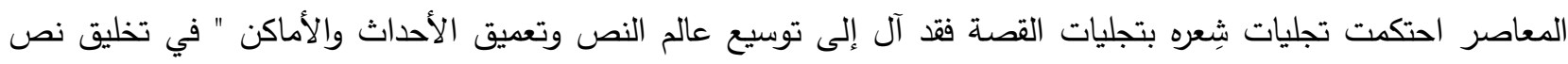

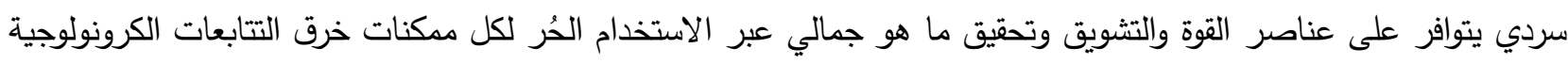

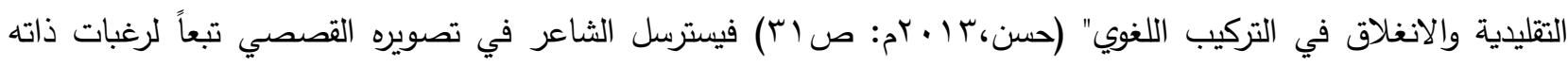

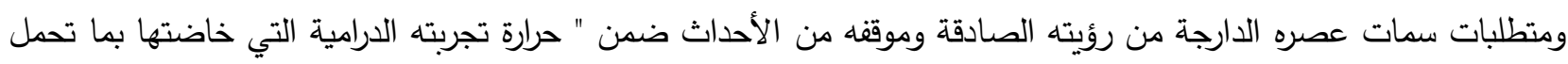

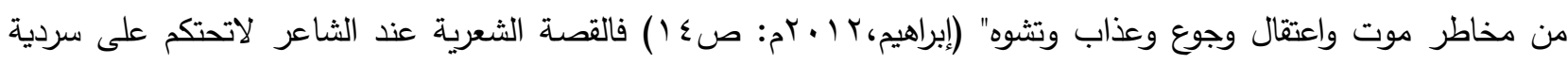

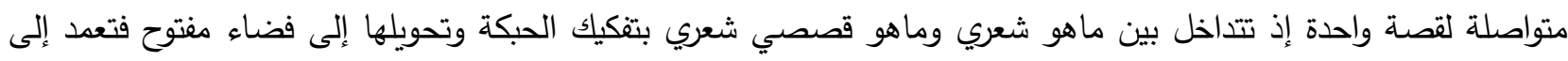

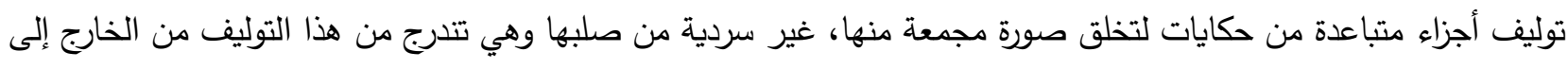

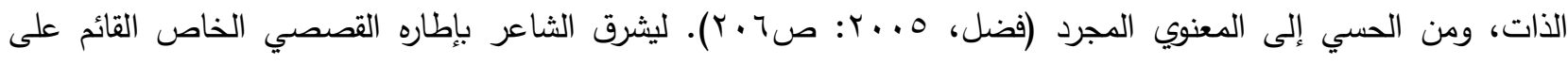

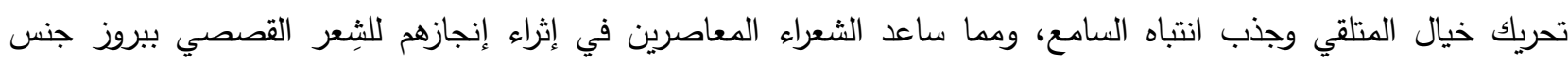

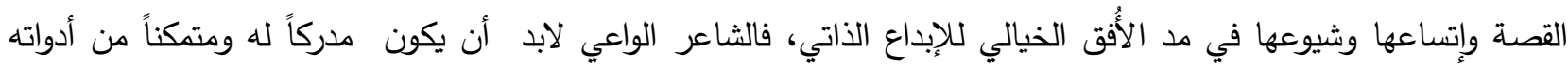

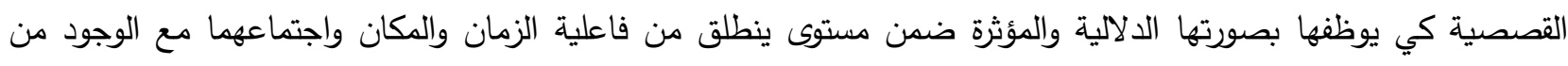
خلال وصفه للحدث بحركته وسكونه كفضاء سردي يكمن فيه التداخل بين الوصف والسرد لأن الحدث " أية واقعة تحدثها

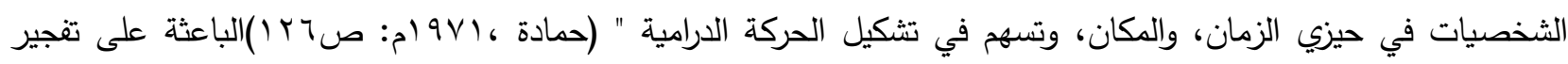

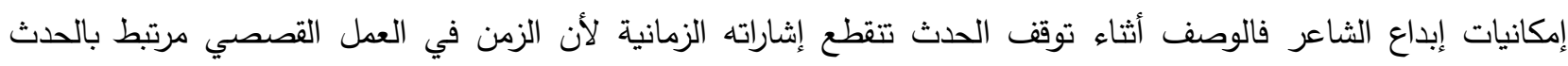

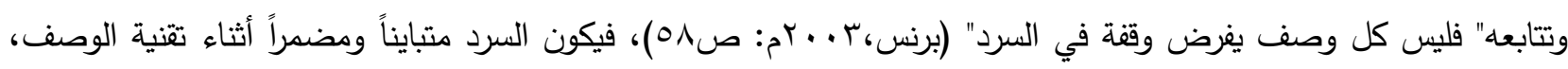
لأنه العنصر الوحيد القادر على تفصيل الصور والتقاطها.

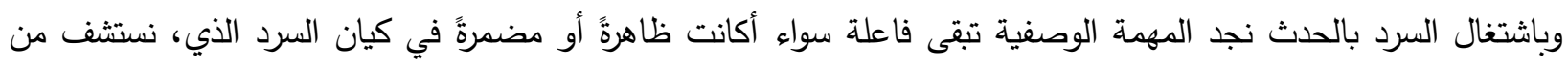

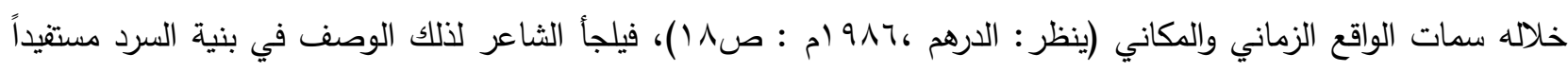

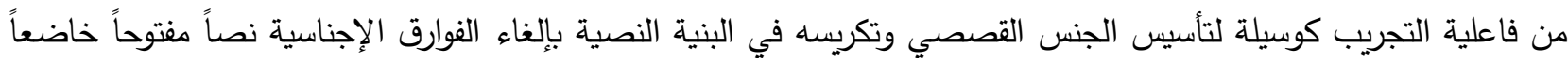

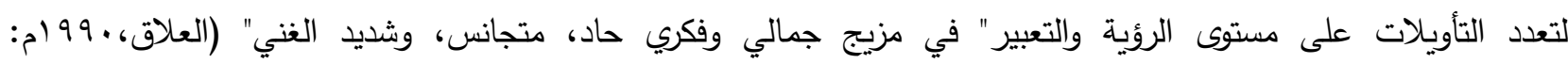

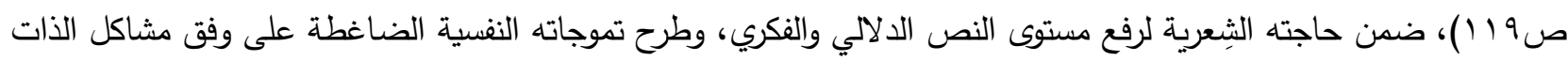

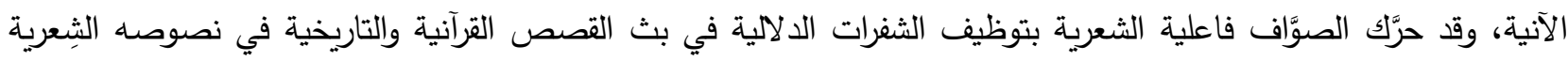

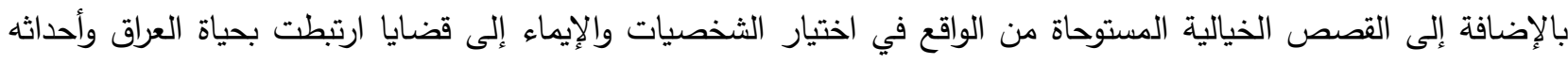

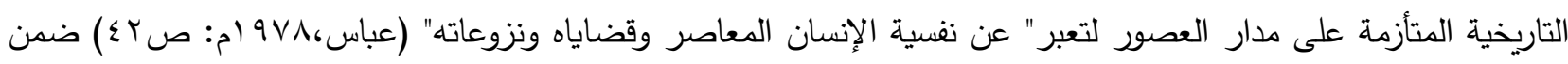

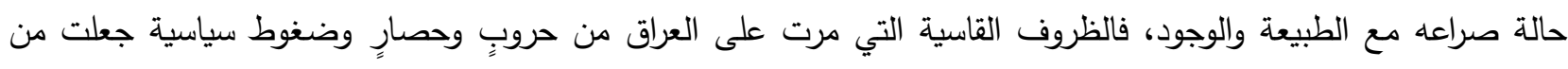

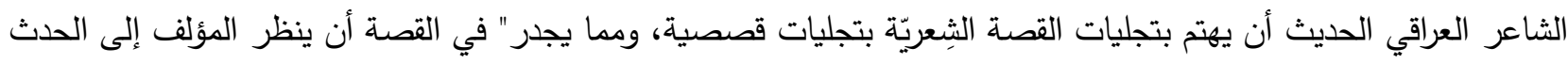

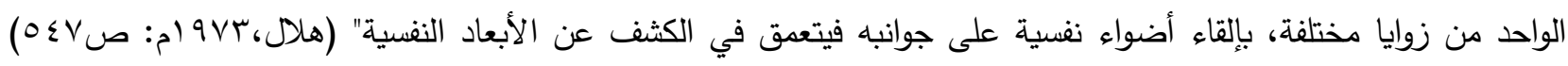


والثعورية داخل شعريته القصصية لأن الواقع المعيش مليء بالمواقف والتناقضات القصصية التي يجدر بالمبدع أن يقف عندها ويخلقها خلقاً جديداً فيحول تلك الأحداث والتصادمات إلى انطلاقة فنية خارجة عن إطار المألوف والمتوارد.

وإذا تأملنا في نص(دائرة الاحتواء) نلحظ أن الأسلوب القصصي يتمحور في الوصف والابتعاد عن سردية القص الغنائية وبث الدفقة الثِعرية التي تكونها المقاطع والجُمل الثعريّة القصيرة بوصفها بنية أسلوبية في آلية التشتيت للنص التصاء) المفتوح، يقول:

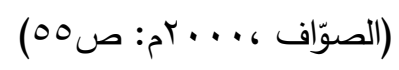

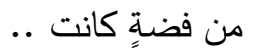
أُنبئت

أن امسك سوار الفضة

بكف السكينة ألقاها إليَّ .. سراعاً تلج باب الضحى، إلى الممر الفاتح للرؤيا.

عملية القص قائمة على البرامج السردية في تثخيص الأعمال وتسارع الأحداث يلتقطها الثاعر بوصفها لقطةً سيميائية سريعة حالما تتتهي تلتحق بوحدة سردية أخرى لأن" لبرامج السردية هي وحدات سردية تتبثق عن تركيب عاملي قابل للتطبيق

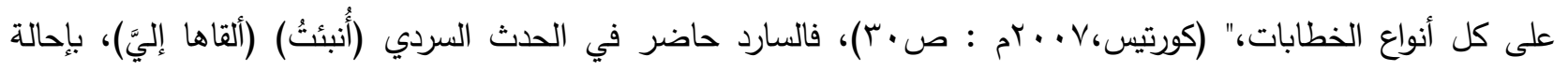

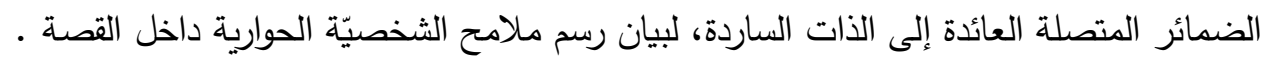
وقد حوّل الثاعر في مشهد المكان المقروء إلى مرئي محاولةً منه في نقل المتلقي معه في رحلة قصصية يحيطها الخيال، وتسليه على مفارقة متوارية خلف المشهد اليومي والمشد الوصفي في تصوير دلالة المكان بصرياً لرؤية باعثة يربط بها الخيال

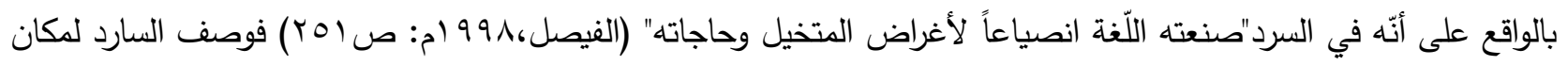

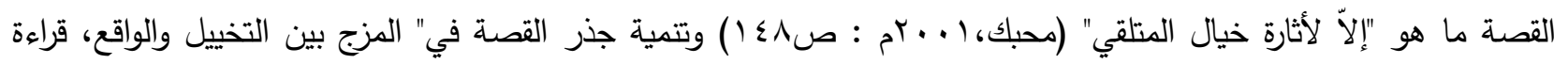

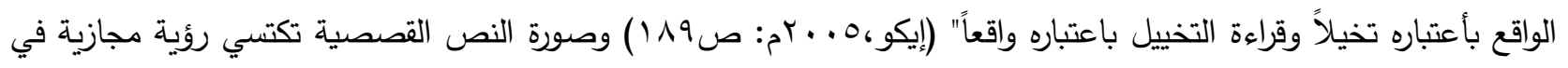
تأثيرها الثعوري بمحاولة الثاعر إبرازه للأحداث الباطنة التي تقترن بمشاكل نفسيّة متعددة ومتشتتة ويعبر عنها بإيحاءات مكونه الدلالي فيوافق ذلك باستثمار التظيم السردي والتمظهر الخطابي على وفق صور "وحدات المضمون القارة المحددة من خلال نواة

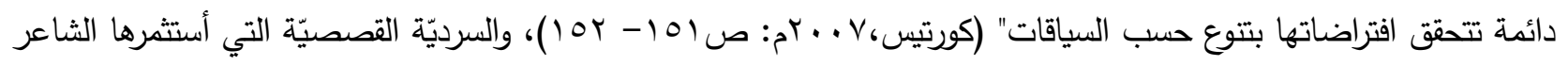
تحمل مجموعة من الطاقات الإشارية الصادرة عن إرادته ووعيه وغايته والتي يسعى بها إلى أختراق ذهن المتلقي وإدراكه للغاية القصصية القص كما مثلت قصص القرآن الكريم المعَين الثَّر الذي استعان به الثاعر في تعضيد نصوصه، فالتقط مشاهد من قصة يوسف

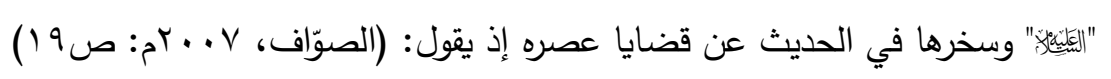




\section{فالبئر القديمة}

يحرسها ذنبّب منتصب القامة

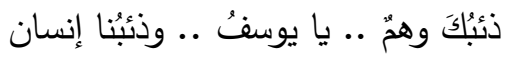

( وخلنا مع يوسفت

في الجبّ

فالتقطته السيارةٌ

وبقينا

جاءوا بقميصٍ لنا

فيه طعم للخديعة

من قال الذئب بريء

سهواً سقطَ القناعُ

وعادَ الذئبُ مزهواً

بالغنيمة

تتوحد حال الواقع مع حال يوسف (اليلّئل) فعناصر الشر قد توحدت في إخوة يوسف عندما تآمروا عليه ورموه في غياهب

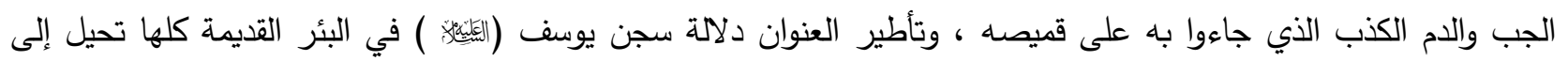
إثارات لقضية العراق وسفك الدماء التي وقعت في البلاد بسبب الحروب المزيفة نقل لنا الصورة القصصية من خلال تشكل الوجه الحقيقي للكثف عن جوهر الرؤية الثِعرية ، وفضائها المكثف "إلى إدراك ما في الأشياء من وجوه كمال يستريح إليها

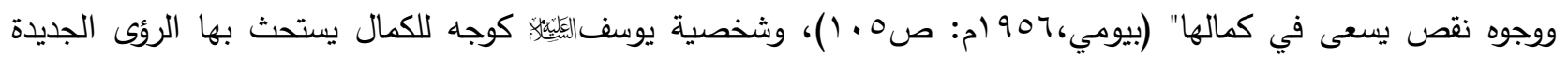
للقضايا المخبئة أي المسكوت عنها ضمن عالمها الوجودي ليواجه بها قضية العصر ومساوئه، ضمن منظوراته الحثيثة للحياة

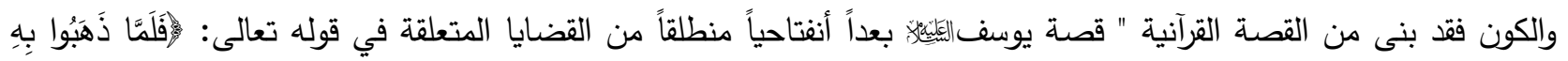

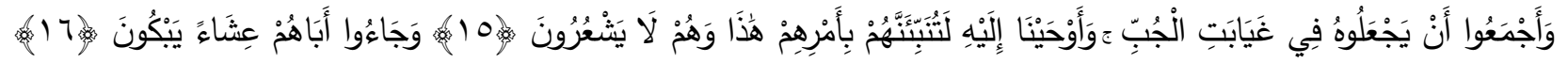

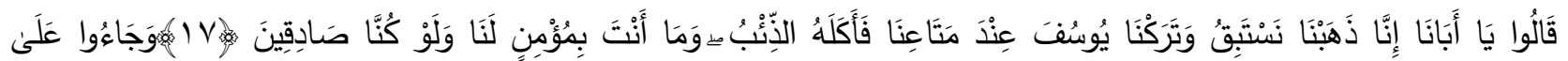

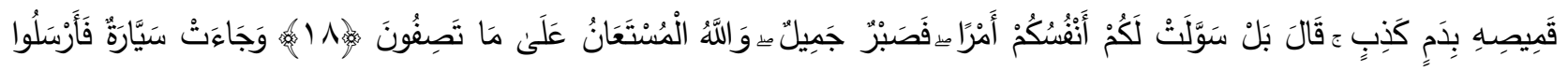

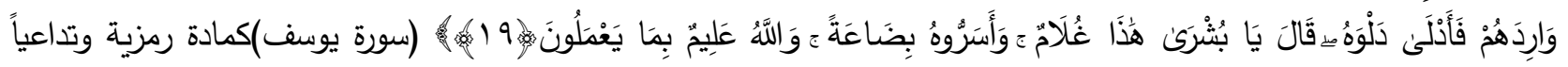


لأحداث تكون شاهداً على رؤاه الفكرية ، ومحركاً نفسياً " حققاً رغباته ومكبوتاته بوسائله الفنية الخاصة" (المختاري ،919 ام: ص (1)، لتصبح مغامرة شِعرية هادفة تمر بأحداثها النسقية على ثلاث مراحل وتشترك معها الذات الثاعرة التي تدخل في مناخ

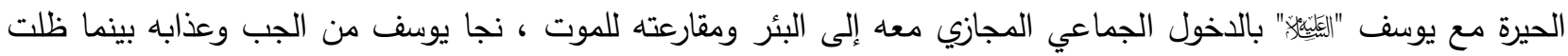
الفئات المضطهدة بالحيرة والبقاء في ذلك الجب، ويحيل بقضية الذئب إلى عقدة القضية المعاصرة والتي تعد فيها 》الحوادث

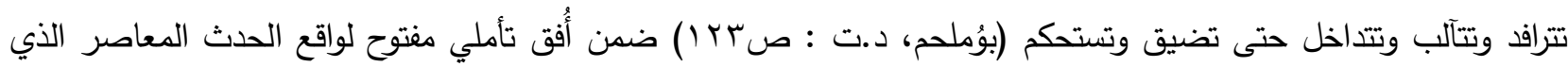
ينزع به إلى تحوير الأحداث بمنظورات جديدة تدخل في توجيه الحراك الثعوري " وهنا تطغى حوادث القصة ووقائعها عن

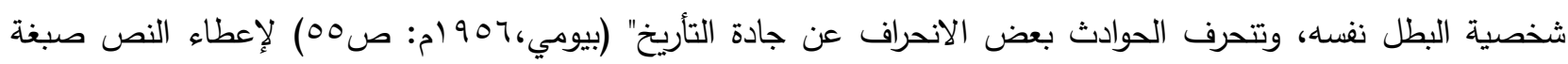
لونية مثيرة في تقابلات أحداث الماضي بالحاضر ونتائجها بإيجابية الماضي وسلبية الحاضر الذي يتغلغل فيه الثِعر الدرامي في

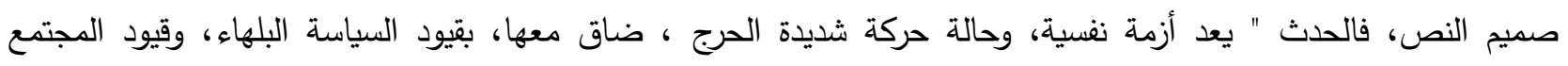
المتزمت" (أمين، د.ت : ص •1 1) وقميص الخديعة والدم الكذب وسقوط الأقنعة عن الوجوه بوضوح الحقيقة والزهو بالغنيمة في

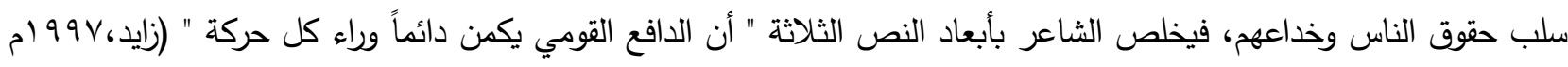
: ص (ء) فالحركة المتتامية في الأسلوب القصصي قائمة على أساس الحدث، كحركة داخلية تدور في فلكه الثخصيات المؤثرة والمتأثرة في فاعلية النص، وجعل الثاعر من قضية يوسف وشخصيته موضع الكمال والخلاص من أزمات المواقف الصعبة

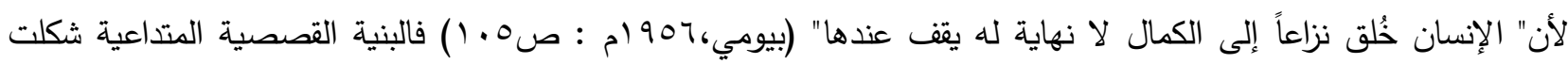

سلسلة متواصلة من التلميحات والتلويحات المتدفقة في اطار الدلالة لتجعل المدلول أكثر إتساعاً وانفتاحاً على محاكاة الواقع. ومن القصص القرآنية التي انفتح عليها الثاعر في نسقه الثعري قصة القتيل الذي أحياه الله سبحانه وتعالى في عهد نبي الله

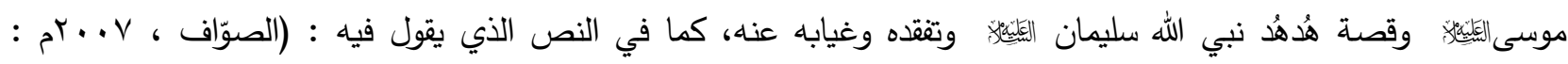
صنז ) وقامَ القتيل يُحصينا كما النجوم قال:

(مالي لا أرى الهدهد فيكم ) ومن سيأتيني من مدن الصحو بأخبار الطفولة

ينفتح الثاعر بنسقه القصصي على إيصال فكرة الأحداث المختلفة التابعة للأزمنة المختلفة ويربطها بالرؤية العقلية لفاعلية القص والتدفق الوجداني الذي مسرحه في أوّل النص بقصة القتيل الذي قام وأحصى الناس بنظراته إذ جسّد صورته القصصية

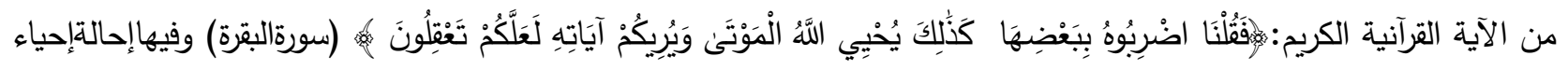




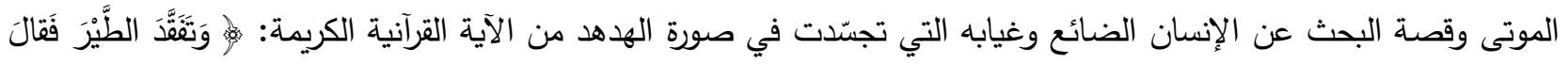

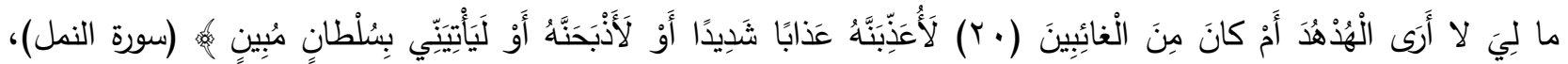

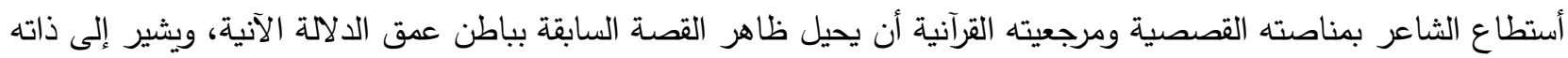

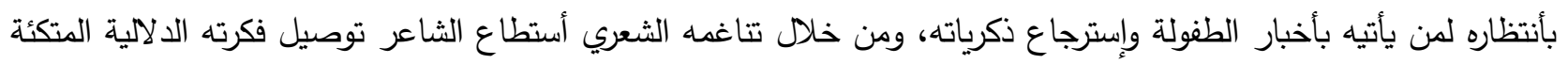

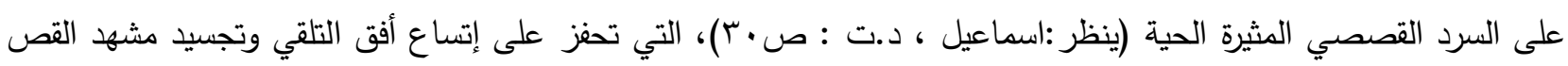
فظاهرة الأرتباط الثعري تخلق جمالية خطابية تخدم فاعلية الدلالة والمعنى تحت أطار الصورة السردية من خلال فاعلية الخيال

$$
\text { والرؤية الثعرية. }
$$

وفي نص (الساعة الواحذة بعد منتصف الحياة)، يسرد الثاعر قصة الدينة وقضية مُلكها وملوكها يقول: (الصوّاف ، ...بم ( صن :

على شفا المدينة المدونة في مخطوطة البردي، المؤيدة بختم العبد الصالح أوتونابشتم المدينة المومياء المسجاة تحت هرم الهنة في وادي الملوك، صاحبة السمو الملكي التي شربت السم - و .. ابتغاء نصرٍ مؤجل، المدينة الأنثى قاصرة الطرف، المقصورة في خيام العشق وفراديس اللذّة، مدينة السلاطين وبلاط المُّلك الملتهب بفيض الألوان على شفا المدينة ... الخيال السحري قوة كامنة في الخوف كوامن الرغبة تفصل بين التقدم إلى الموت أو التقهر إلحياة، زمن المخطوط يشير إلى الواحدة، إلا أن هناك ما يحول بين المرو وقلبه، ذات طرق مجهولة أعرفها جيداً

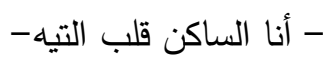

يعدد الثاعر في قصة الدينة من خلال الرمز الأسطوري والإشارة إلى حضارتها العريقة، وتزاحم الأحداث في سردية النص

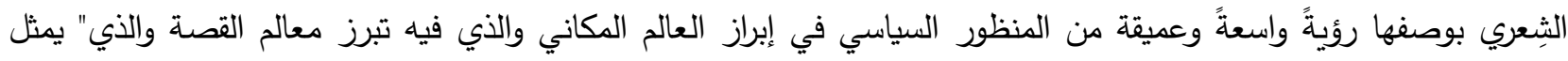

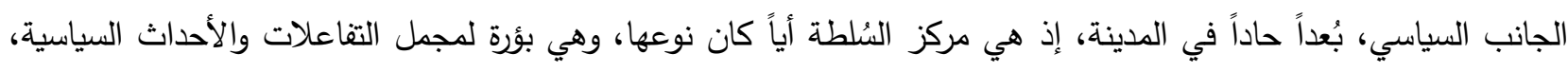

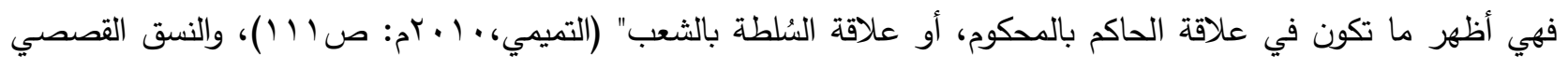




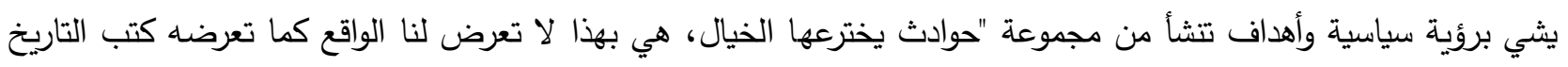

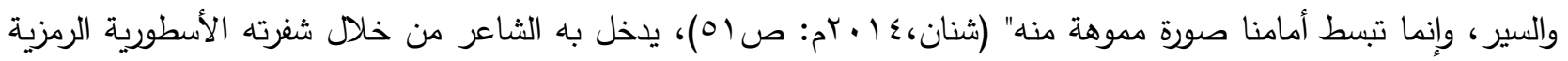

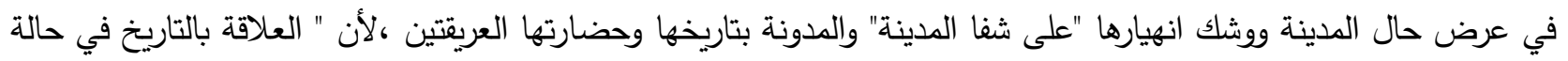

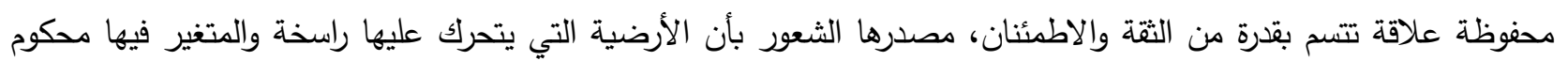

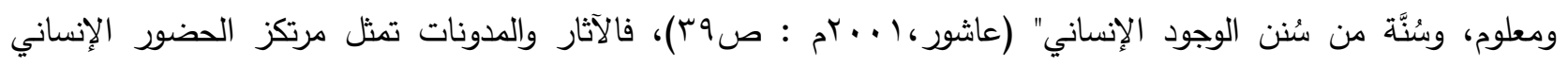

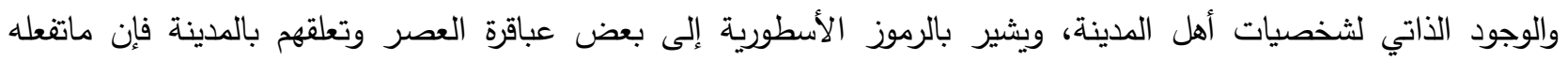
الثخصية القصصية في تكوين الأحداث يجعلها علاقة تكاملية وجانبا فعالا في مستلزمات المنطق القصصي، لأن الأنسات الأختباء وراء

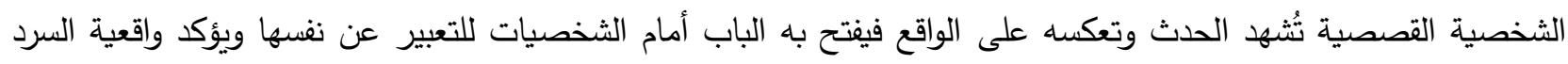

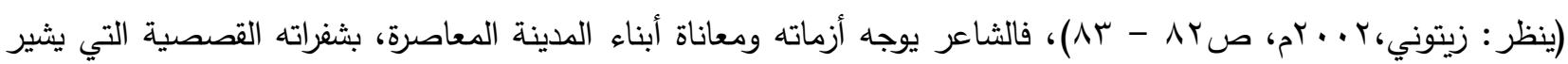

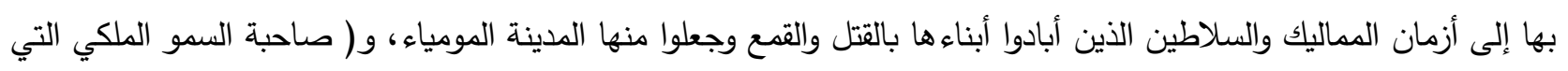

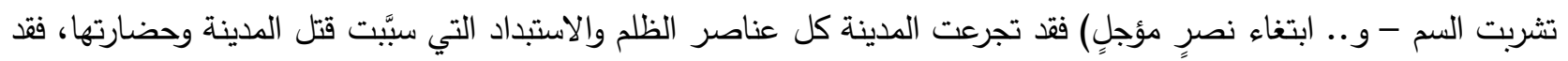

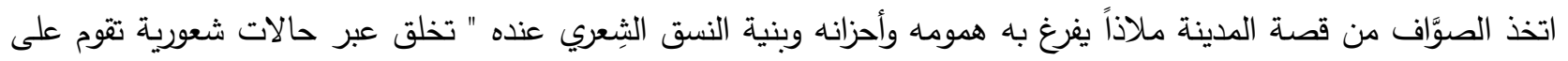

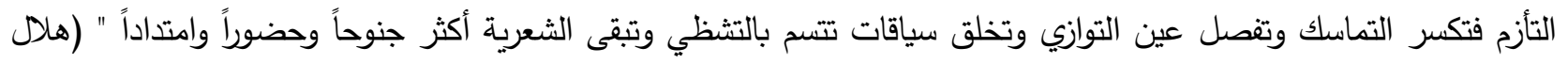

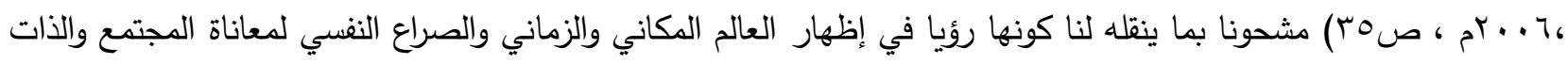

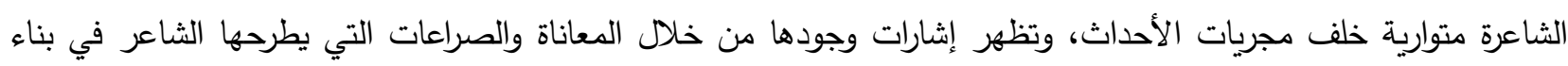

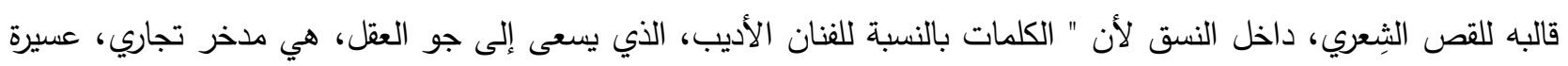

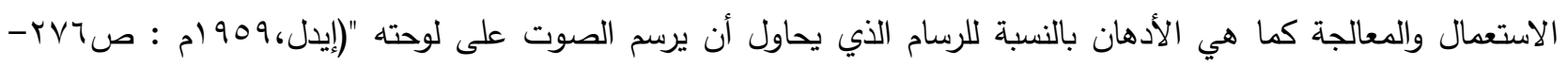

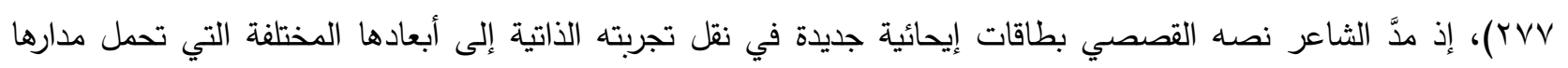

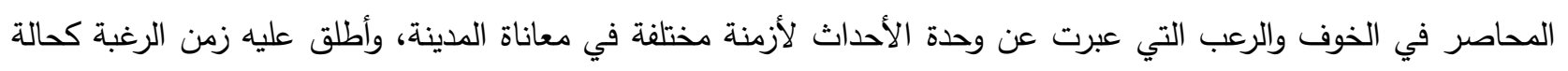

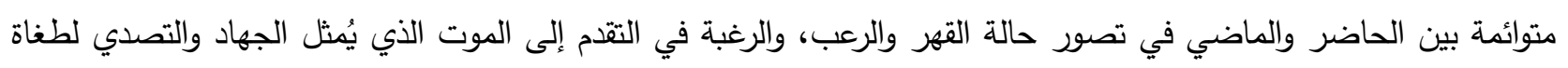

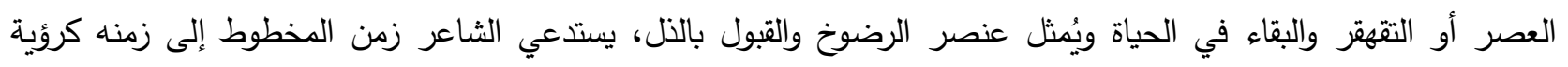

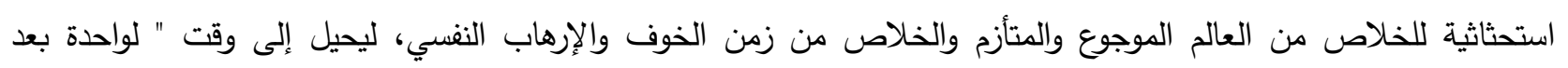

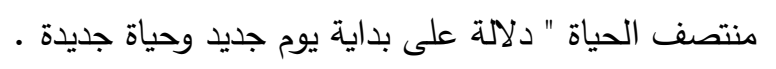

وفي ظلّ ما تقدم نجد أن الثاعر عمد الى الترتيب بين الوظائف، وبين ما يسمى نقديا بشبكة العلاقات بين الثرائح الككونة

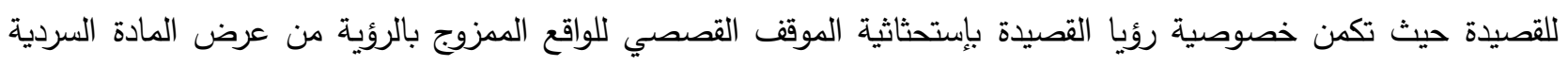

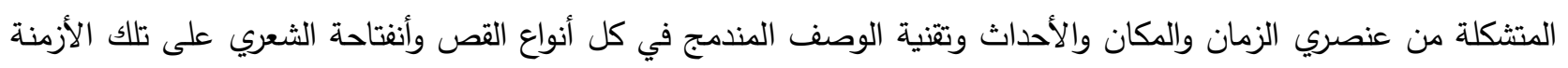

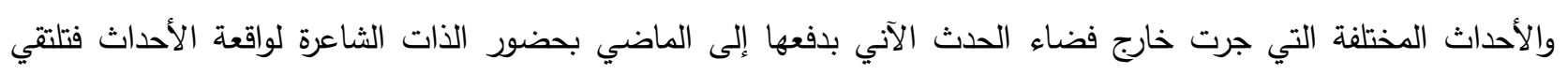

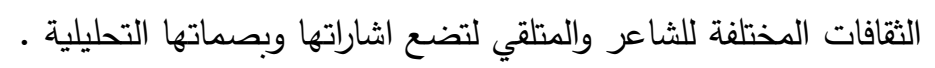




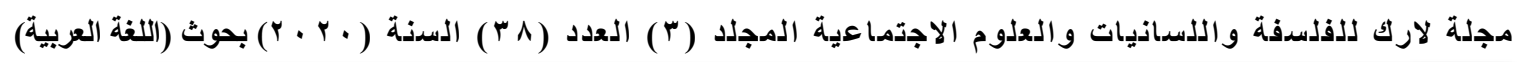
أوّلاً : المجموعات الثعريـة

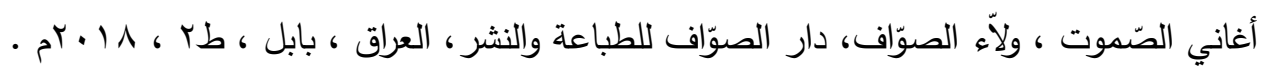
كاميكاز ، ولا الصوّاف ، مكتب الغسق للحاسبات، العراق ، بابل ، طا ، . . بـ . كفن شهريار ، ولاّه الصوّاف ، دار الصوّاف للطباعة والنشر ، العراق ، بابل ، طا ، V . . rم . ثانياً ـ القرآن الكريم ـ ـ الكتب

آليات السرد في الثِعر العربي المعاصر، د.عبدالناصر هلال ، مركز الحضارة العربية ، القاهرة ، طا ، 7 . . ب م • اتجاهات الثِعر العربي المعاصر ، إحسان عباس ، سلسلة كتب عالم المعرفة ، أصدار المجلس الوطني للثقافة والفنون والأدب ،

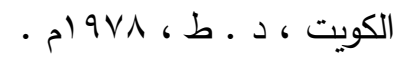
أرسطو، د. مصطفى غالب ، منشورات دار ومكتبة الهلال ، بيروت ـ لبنان ، د. ط ، 9V9 ام . استدعاء الثخصيات التراثية في الثعر العربي المعاصر ، د. علي عشري زايد ، دار الفكر العربي ، القاهرة ، د ـ ط ، و99 ام بناء الرواية العربية السورية (·191 ـ ـ991 م ) ، د. سمر روحي الفيصل، أتحاد الكتاب العرب ، سوريا ، د.ط ، 991 ام • تاريخ القصة والنقد في الأدب العربي ، السباعي بيومي ، مكتبة الأنجلو المصرية ، طا ، 907 ام . تحولات المدينة في الثِّر العراقي الحديث (1901 1 م ـ .191 م ) ، د. عبد الله حبيب التميمي ، دار الرائي للدراسات والترجمة

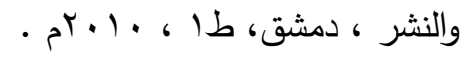

تحولات النص السردي العراقي، الناقد عبد علي حسن ، الناقد عبد علي حسن ، من أصدارات مشروع بغداد عاصمة الثقافة

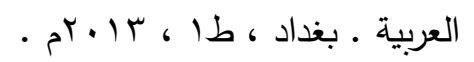

تداخل الفنون في القصيدة العراقية الحديثة دراسة في شعر مابعد الستينيات ، كريم شغيدل ، دار الثؤون الثقافية العامة ، بغداد ، .

جمالياتُ الحرية في الثِعر المعاصر، د. صلاح فضل، مطابع العبور الحديثة ، أطلس للنشر والإنتاج الإعلامي ، القاهرة ،

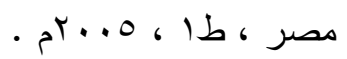

جماليات النص الثِعري في شِعر يحيى السماوي ( شعر التفعيلة أنموذجاً ) ، علي كتيب ، تموز للطباعة والنشر ، دمثق ، طا . $5^{r \cdot 106}$ 


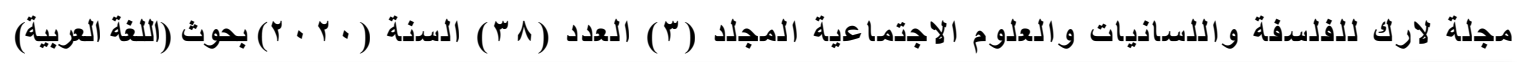

الحكاية الثعبية العراقية (دراسات ونصوص) ، كاظم سعد الدين ، الجمهورية العراقية ، وزارة الثقافة والفنون ، الرشيد للنشر ،

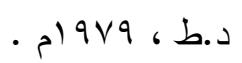

الحكاية والتأويل دراسات في السرد العربي، عبد الفتاح كيليطو، دار توبقال للنشر ، الدار البيضاء ، المغرب ، طا ، 911 ام . الخطاب الثِّري الحداثوي والصورة الفنية ( الحداثة وتحليل النص ) ، د. عبد الإله الصائغ ، المركز الثقافي العربي ، الدار

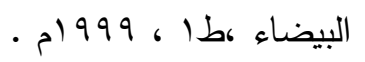

دراسات في الثِعر والفلسفة ، د. سلام كاظم الأوسي ، دار نيبور للطباعة والنشر والتوزيع ، ديوانية ـ العراق ، طا ، با • بم . دراسات نقدية من الأسطورة إلى القصة، د ـ محمد زياد محبك، منشورات دار علاء الدين ، دمشق ، سوريا ، طا ، 1. بrم . الذات في مواجهة العالم تجليات الأغتراب في القصة القصيرة في الجزيرة العربية ، د. أميرة علي الزهراني ، المركز الثقافي

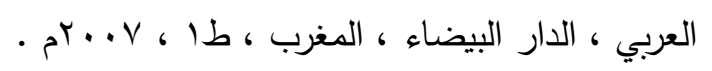

روح العصر دراسات نقدية في الثعر والمسرح والقصة ، د. عز الدين إسماعيل ، دار الرائد العربي ، بيروت ، لبنان ، طا، .

الثعر العربي المعاصر قضاياه وظواهره الفنية والمعنوية ، د ـ عز الدين اسماعيل ، دار الفكر العربي العربي ، القاهرة ، ط؟ ،

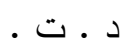

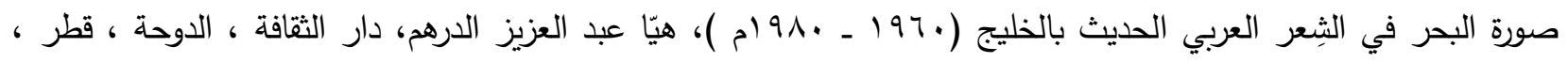

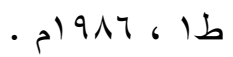

علم المعنى (الذات، التجربة، القراءة)، د. رحمن غركان ، دار الرائي للدراسات والترجمة والنشر ، دمثق ، طا ، 1. .بم .

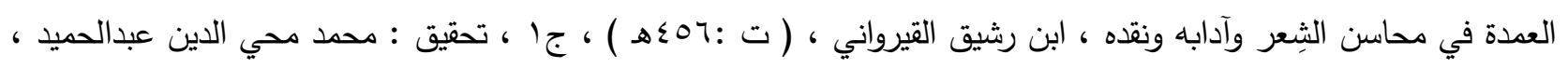

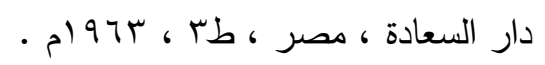

في الأدب وفنونه ، علي بومُلحم ، المطبعة العصرية للطباعة والنشر ، صيدا ، لبنان ، د. ط ، د. ت. في النقد التطبيقي صيادوا الذاكرة ، رضوى عاشور، المركز الثقافي العربي ، الدار البيضاء ، المغرب ، طا، ل ..بم . في تحليل الخطاب، د. حاتم عبيد ، دار ورد الأردنية للنشر والتوزيع ، الأردن ، طا ، ؟ ا. بام. في حداثة النص الثِتري دراسات نقدية ، د. علي جعفر العلا ق ، وزارة الثقافة والاعلام ، دار الثؤون الثقافية العامة ، بغداد ،

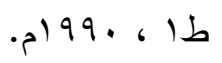

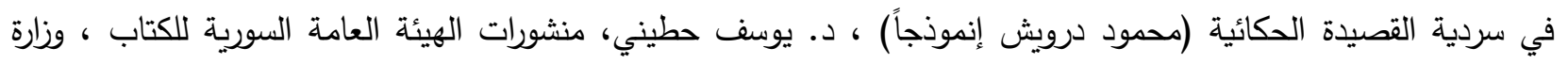

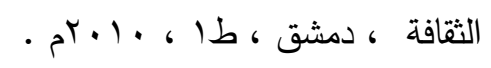




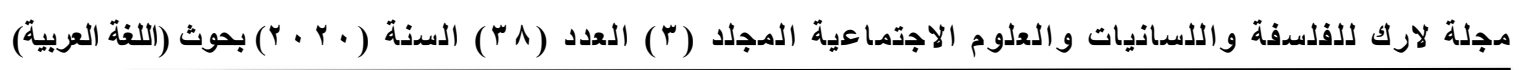

القصة السيكولوجية دراسة في علاقة علم النفس بفن القصة ، ليون إيدل ، ترجمة : د. محمود السمرة ، منشورات المكتبة

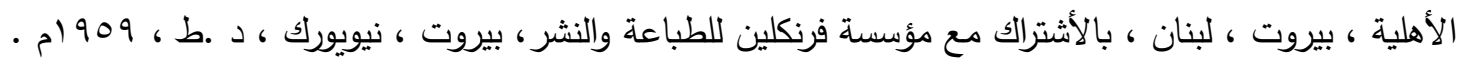
القصص في الأدب العراقي الحديث ، عبد القادر حسن أمين ، مطبعة المعارف ، بغداد ، د. ط ، د. ت . قصيدة النثر من بودلير إلى أيامنا، سوزان بيرنار، ت: د. زهير مجيد مغامس، مراجعة : د .علي جواد الطاهر ، دار المأمون

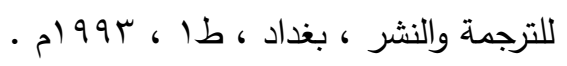
لذة التجريب الروائي، د. صلاح فضل ، أطلس للنشر والأنتاج الأعلامي ، القاهرة ، طا، 0. . ب م .

مدخل إلى السيميائية السرديّة والخطابية ، جوزيف كورتيس ، ترجمة : جمال حضري ، منشورات الأختلاف ، الجزائر ، طا ، . ، $\cdot a^{\prime} \cdot v$ المدخل إلى نظرية النقد النفسي سيكولوجية الصورة الثعرية في نقد العقاد انموذجاً ، زين الدين المختاري ، منشورات أتحاد العرب

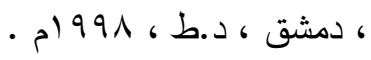
مدخل لدراسة الثِعر العربي الحديث، د. إبراهيم خليل، دار المسيرة للنشر والتوزيع والطباعة ، عمان ، الأردن ، طب ، V... Y م مرايا نرسيس ، الأنماط النوعية والتشكيلات البنائية لقصيدة السرد الحديثة ، د. حاتم الصكر، المؤسسة الجامعية للدراسات

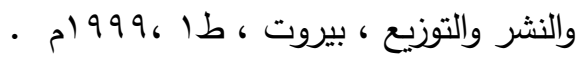

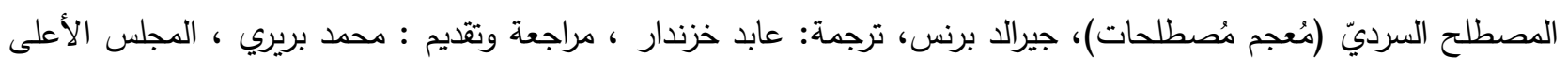

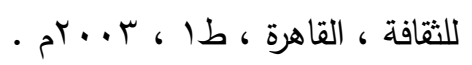
معجم المصطلحات الدرامية والمسرحية ، إبراهيم حمادة ، مطبوعات دار الثعب ، القاهرة ، د. ط ، الVام . معجم مصطلحات نقد الرواية ، د. لطيف زيتوني ، مكتبة لبنان ناشرون، بيروت ، طا ، r +. بr • المغامرة الجمالية للنص القصصي سلسلة مغامرات النص الإبداعي ، أ ـ د. محمد صابر عبيد ، عالم الكتب الحديث ، أربد ،

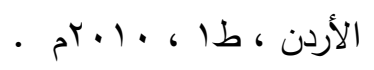

نزهات في غابة السرد، أمبرتو إيكو ، ترجمة : سعيد بنكراد ، المركز الثقافي العربي ، الدار البيضاء ، المغرب ، طا ، . النقد الأدبي الحديث، د. محمد غنيمي هلال ، دار العودة ، بيروت ، د ـ ط ، سVV ام . الرسائل والأطاريح

الحضور النقدي عند رضوى عاشور، إسراء أبو ضاري شنان، (رسالة ماجستير)، إشراف . د. فرح مهدي صالح، جامعة

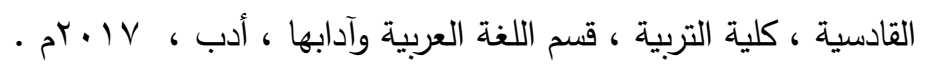




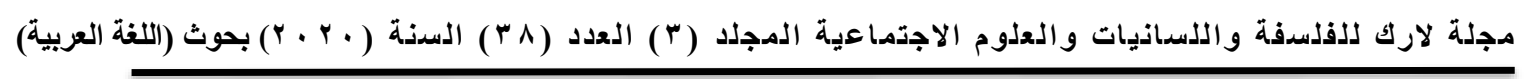

المجلات والدوريات

الحضور والغياب في ديوان محمود دروي( لاتعتذر عمّا فعلت ) ، د. عبد الخالق عيسى ، جامعة النجاح الوطنية ، فلسطين ،

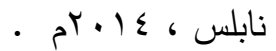

r. الرواية العراقية رصد الخراب العراقي في أزمات الدكتاتورية والحروب والاحتلال وسلطة الطوائف، سلام إبراهيم، مجلة تبيّن

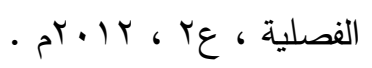

